\title{
La Expansión Regional de la Masonería en Nuevo León, México,1905-1911
}

\section{The Regional Expansion of Freemasonry in Nuevo León, Mexico, 1905-1911}

\author{
Antonio Garza Martínez \\ Universidad Autónoma de Nuevo León, México \\ angmahr@outlook.com
}

Recepción: 5 de julio de 2019/Aceptación: 23 de agosto de 2019

doi: https://doi.org/10.15517/rehmlac.v11i2.36427

\section{Palabras clave}

Bernardo Reyes; expansión urbana; masonería, Nuevo León; uso de la tierra.

\section{Keywords}

Bernardo Reyes, Freemasonry, Land use, Nuevo Leon, Urban development.

\section{Resumen}

El presente trabajo pretende entender la lógica de expansión regional de la masonería en el estado de Nuevo León una vez conformada la Gran Logia del Estado de Nuevo León, que derivó en una organización del tipo de jurisdicciones territoriales de los talleres de su obediencia. Este patrón de organización se entiende como parte del uso y de la ocupación socio-espacial de la ciudad y en una escala mayor, del territorio político del estado de Nuevo León, toda vez que se comprende el contexto histórico del momento dentro del marco cronológico propuesto para este estudio.

\section{Abstract}

The present aims at understanding the system underlying the regional expansion of freemasonry in the state of Nuevo León since the foundation of the Grand Lodge of the State of Nuevo León. It derived into an organizational logic of territorial jurisdiction in which its symbolic lodges pledge obedience, use and socio-spatial occupation of the city and the political territory of the state, thus explaining the historical context within the framework of this paper. 


\section{Introducción}

La ocupación socio-espacial de territorio es una forma de apropiación y uso del mismo. El ser humano en sus actividades ha desarrollado formas y patrones de ordenamiento del territorio y del espacio, desde la configuración de las ciudades, hasta el ordenamiento en su traza urbana, la organización de sus actividades y el uso de las mismas por los propios habitantes.

El presente trabajo se desarrolla en el contexto del Estado de Nuevo León durante el gobierno del general Bernardo Reyes, mismo que a su vez estuvo inserto en el período de gobierno del presidente Porfirio Díaz. Si bien, la masonería en el Estado empezó sus actividades desde $1828^{1}$, fue hasta las postrimerías del período de gobierno reyista que la masonería en el Estado se reorganizó y recibió un impulso inusitado por un período de seis años, de los cuales cuatro corresponden cuando todavía gobernó el general de División Bernardo Reyes y los otros dos corresponden al gobierno interino del general de División José María Mier.

En lo que respecta al Estado de Nuevo León, en este período previo de la masonería a la organización por confederaciones de grandes logias masónicas se observa por medio de recopilación de datos, registros e interpretación de los mismos que la lógica de expansión regional de la masonería en el Estado de Nuevo León, una vez conformada la Gran Logia del Estado de Nuevo León, fue del tipo de jurisdicciones y demarcaciones territoriales, similar a la organización de las autoridades civiles.

De la observación de la forma en que se organizaron las logias masónicas y de su obediencia a organismos de mayor jerarquía, se infieren patrones de organización que se pueden entender también como parte del mismo uso y de la ocupación socio-espacial de la ciudad, pero dada la tendencia de la masonería de expandirse en los territorios de las entidades federativas, en una escala mayor, es posible la comprensión de contextos históricos del momento que están dentro del marco cronológico propuesto para este estudio.

\section{Antecedentes}

En el Estado de Nuevo León la masonería tuvo un importante impulso durante los últimos años del régimen del general Porfirio Díaz, siendo gobernador el general Bernardo Reyes (1885-1887, 1889-1900, 1903-1909). De acuerdo con el autor y masón, Luis J. Zalce y Rodríguez, en su libro Apuntes para la Historia de la Masonería en México (De mis lecturas y mis recuerdos), hacia 1880 ya operaban en el Estado otras logias antes de la fundación y consolidación de la Gran Logia de Nuevo León que actualmente sigue operando. En este contexto, registró que en la época operaban más o menos regularmente:

1 Ernesto de Villarreal Cantú, Trabajo Potente, Vida Inmaculada: Medio Siglo de Cultura Masónica, 1905-1955 (Monterrey: Imprenta de la Gran Logia del Estado de Nuevo León, 1956), 90. El autor refiere un Boletín Masónico que publicó hacia 1828 el Rito Nacional Mexicano, correspondiente al 25 de abril, en el que se menciona "el funcionamiento de la Logia "PERFECTA UNION" No. 8 en este Or.. de Monterrey, en la que actuaban como Ven. $\therefore$ Maest.. Prim. $\therefore$ y Seg. $\therefore$ Vigilantes, los HH. . Irineo Castrillón, Julián de Arrese y Rafael de la Garza." [sic]. Sin embargo, aunque el autor no menciona la fuente principal, para el momento en que refiere la información, año de 1956, refirió que el Sr. Eugenio Castillón tenía en su archivo personal documentos sobre este respecto y que por aquel entonces estaban en poder de su hijo, Óscar Castillón. Actualmente se ignora el paradero de estos documentos. 
Las respetables logias simbólicas "Fraternidad"No. 1 en Villaldama; "Tolerancia Masónica" No. 6, en Monterrey; "Progreso" No. \%, en Cadereyta fiménez; "Unión Perpetua" No. 8, en Linares; "Juan Ignacio Ramón” No. 26, en Lampazos de Naranjo; "Doctor Mier" No. 36, en Monterrey; "General Zuazua" No. 75, en Lampazos de Naranjo; "Estrella de Oriente” No. 81, en el mismo Lampazos; "Hiram" No. 116 y "Unión y Constancia” No. 129, en Monterrey y "Nuevo León" No. 156, en Villa de Santiago."

Así mismo, Luis J. Zalce y Rodríguez menciona que de todas estas logias había algunas que dependieron de la Gran Logia "Unida Mexicana" de Veracruz, otras tantas de la Gran Logia "Valle de México", y finalmente, las logias "Juan Ignacio Ramón” No. 26, “General Zuazua” No. 75, y "Estrella de Oriente” No. 81, todas ellas en Lampazos, dependían del "Gran Oriente" . Estas últimas tres logias se constituyeron hacia enero de 1885 en la Gran Logia del Estado "Felipe Naranjo Garza" que, bajo la dirección del Sr. Nemesio G. García como gran maestro, quedó subordinada al "Gran Oriente", siendo así, de acuerdo con el autor, la primera Gran Logia en Nuevo León. ${ }^{4}$

Al respecto conviene revisar la información que presentó el autor y masón Ernesto de Villarreal Cantú en su libro Trabajo Potente, Vida Inmaculada: Medio Siglo de Cultura Masónica, 1905-1955, considerando que esta publicación está centrada principalmente en la historia de la masonería nuevoleonesa. Después de que Ermilo G. Cantón y sus simpatizantes fundaran el "Gran Oriente de México", el Supremo Consejo del Grado 33 del Rito Escocés Antiguo y Aceptado emitió el 27 de mayo de 1883 un documento titulado Balaustres No. 32. Este documento menciona puntos que resultan de interés para este trabajo sobre las pautas de jurisdicción territorial, conformación y administración de las grandes logias, además de sus facultades. A continuación, cito los puntos completos del documento por considerar que ayuda a comprender el contexto:

2 Luis Zalce y Rodríguez, Apuntes para la Historia de la Masonería en México (De mis lecturas y mis recuerdos) Primer Tomo (Ciudad de México: Talleres Tipográficos de la Penitenciaría del Distrito Federal 1950), 443.

3 Rogelio Aragón, "Porfirio Díaz y la «Gran Dieta Simbólica» ¿La masonería mexicana bajo control?”, REHMLAC+ 7, no. 2 (diciembre 2015 - abril 2016): 141, http://dx.doi.org/10.15517/rehmlac.v7i2.22695. El autor lo refiere como el "Gran Oriente de México" que fundó Ermilo G. Cantón y sus simpatizantes hacia enero de 1879 después de su ruptura con el Supremo Consejo del Grado 33 del Rito Escocés Antiguo y Aceptado.

4 Zalce, Historia de la Masonería, tomo I, 443. Así mismo en De Villarreal, Trabajo Potente, 90-95, se menciona que el hermano Remigio Véliz en un trabajo que presentó en junio de 1952 en la logia simbólica “Obreros del Silencio" No. 1, refirió que "por esos mismos años, o sea de 1883 a 1890 ya existía Monterrey la Gran Logia de Estado "UNION", la que fuera reconocida en 1890 por la Gran Dieta Simbólica como Gran Logia en el Estado de Nuevo León con el Núm. 7” [sic]., 91 Y refirió una Gran Pl. $\therefore$ fechada el 4 de Diciembre de 1884 dirigida por los hermanos E. Panbrico y C. Sánchez, en su carácter de gran maestro y gran secretario de la Gran Logia "Unión" respectivamente, con objeto de felicitar cordialmente al nuevo Alto Cuerpo. Además, menciona el autor Ernesto De Villarreal Cantú que el hermano Prudencio Olivares hizo un aporte tratando de esclarecer el asunto de cuál fue la primera gran logia en Nuevo León, mencionó otra comunicación por los mismos hermanos a la nueva Gran Logia Felipe Naranjo Garza No. 12 con fecha del día siguiente (5 de diciembre de 1884), pedía que los elementos de las logias de Lampazos y sus propios talleres cubrieran a la Gran Tesorería de la Gran Logia "Unión" los adeudos por distintos derechos relacionados con su obediencia y jurisdicción. Por último, Ernesto de Villarreal Cantú mencionó que ambas cartas están en uno de los Expedientes del Archivo de la Gran Logia del Estado de Nuevo León. Por último, el libro del masón Luis J. Zalce y Rodríguez se publicó hacia 1950, en tanto que el libro del masón Ernesto de Villarreal Cantú hacia 1956, además de centrarse específicamente en la historia de la masonería nuevoleonesa. Hay un trabajo que al mismo tiempo refiere esta información y que escribió el arquitecto y masón, Juan Alanís Tamez, con motivo del centenario de la logia "General Mariano Escobedo" No. 9 de Santiago, Nuevo León, titulado Centenario de la Resp. : Log. . Simb. : "Gral. Mariano Escobedo" No. 9 Or: $:$ de Santiago, N.L. 1905-2005, (Monterrey: Imprenta de la Gran Logia del Estado de Nuevo León, 2005), 5.

5 De acuerdo con la terminología masónica, balaustre es un documento redactado por los altos grados. Respetable Logia Simbólica Libertadores No. 434. "Glosario de términos masónicos", https://logialibertadoresblog.wordpress.com/glosario-de-ter$\underline{\text { minos-masonicos/ }}$ 
$1^{o-S e}$ deroga el Balaustre No. XXX de 25 de abril del corriente año.

$2^{o-E l ~ S u p r e m o s ~ C o n s e j o ~ r e n u n c i a ~ a ~ f a v o r ~ d e ~ l a s ~ G r a n d e s ~ L o g i a s ~ d e ~ E s t a d o ~ e x i s t e n t e s ~ y ~ q u e ~}$ se formen en lo sucesivo, la jurisdicción que sobre el SIMBOLISMO [sic] le confieren nuestras Constituciones, en consecuencia, estos Cuerpos, al asumir las facultades del Supremo Consejo sobre las Logias, se hacen responsables ante el mundo masónico del orden, disciplina, moralidad, progreso y firmeza de todo el Simbolismo de la República.

$3^{\circ}$-Esta transmisión de poderes tendrá efecto desde el 24 de junio próximo en adelante y PARA SIEMPRE [sic].

$4^{\circ}$-Las Grandes Logias ejercen jurisdicción exclusiva sobre los grados simbólicos dentro de los límites políticos de su respectivo Estado o Territorio, y sobre las siguientes bases indeclinables:

I.-Inviolabilidad de los dogmas de nuestra augusta Institución.

II.-Conservación inalterable de las fórmulas, rituales, juramentos Ssig.๑. TंТo.๑. y Ppal. : que nos son conocidos.

$5^{\circ}$ Las Logias que no tengan Gran Logia, mientras organizan este Cuerpo según las Constituciones vigentes, y desde el 24 de junio próximo en adelante, quedan bajo la jurisdicción de la que les sea más cercana o de la más antigua, si hay dos o más equidistantes de aquéllas.

$6^{0}$-Las Logias del Distrito Federal procederán a formar su Gran Logia conforme a lo preceptuado en nuestras Constituciones, verificando sus elecciones e instalación solemne el día 15 del próximo junio a las 7 de la noche en el Templo conocido.

$7^{\circ}$-Desde la fecha señalada en el Art. $3^{\circ}$ todas las Grandes Logias de Estado, tienen facultad de constituirse libremente y en armonía con los preceptos, usos y prácticas antiguas y comunmente [sic] admitidas para la Masonería Simbólica. Sus Constituciones serán publicadas a la mayor brevedad posible.

$8^{\circ}$-Las Grandes Logias, al adquirir su más completa independencia, dentro de los límites de su respectiva jurisdicción, quedarán constituidas con el amplísimo carácter de Gran Logia de Libres y Aceptados Masones, pudiendo, por lo tanto, sólo ellas en los términos de su jurisdicción expedir patentes y diplomas a todos los Ritos Regulares, para trabajar en los grados correspondientes a los Simbólicos del A. A. E. y hacer participantes d sus trabajos a las Dignidades y Oficiales de los Talleres de estos Ritos.

$9^{\circ}$-El Supremo Gran Consejo se reserva la expresamente su jurisdicción sobre las Logias del Grado $4^{\circ}$ en adelante.

10º-La Cámara de Logias del Supremo Consejo cesará en sus funciones el 24 de junio próximo. 
11-2uedan derogadas nuestras Constituciones Generales y Balaustres anteriores, en todo lo que se opongan al presente, desde el 24 de junio próximo.

\section{TRANSITORIO}

Circúlese a todos los Cuerpos de nuestra furisdicción y a las Grandes Logias y Supremos Consejos extranjeros.-

Dado y promulgado en el Valle de México a los 27 días del mes de mayo de 1883 e.:v. - - Gral. Carlos Pacheco. - Gral. MARIANO ESCOBEDO. - Lic. Alfredo Chavero. Fosé F. Bulman. Francisco D. Marcin. Fosé G. Malda. Ignacio Pombo. Gral. PORFIRIO DÍAZ. Gral. MANUEL GONZÁLEZ. Lic. Ignacio Mariscal. Luis Pombo. Fulio Zárate. Fulio H. González. Francisco Troncoso. W. H. Keller. Fosé Ma. Gaona. E. Chazari. Eugenio Chavero. Todos grado 33.- Nos el Soberano Gran Maestro de la Orden Alfredo Chavero.- Timbrado y sellado por Nos, el Gr.. Can. Guarda Sellos. - Fulio Zárate.- Por mandato del Supremo Consejo, No. el Gran Sec.: General del mismo.- Eugenio Chavero. ${ }^{6}$

De lo anterior se infiere que en primer lugar, la manera en que las grandes logias llegaron a tener autonomía dentro de sus jurisdicciones territoriales (en el caso de México, una gran logia por cada Estado) siempre respetando los preceptos de las constituciones masónicas; en segundo lugar, se puede apreciar que además de respetar dogmas fórmulas y rituales, entre otras cosas, también quedaron constituidas como autoridades reconocidas dentro del mundo masónico (orden, disciplina, moralidad, progreso y firmeza); finalmente, cada una de las grandes logias estatales emitió un reglamento o constitución que rige a las demás logias simbólicas dentro de su jurisdicción territorial, quedando además autorizadas para expedir patentes y diplomas a todos los ritos regulares.

Este documento en sí, además de dejar en libertad de operación a las grandes logias de estado dentro de los límites políticos de cada entidad federativa y, como se dijo unas líneas arriba, sobre las condiciones indeclinables de inviolabilidad de los dogmas, fórmulas, rituales, juramentos, signos, tocamientos y palabras, nos permite entender una manera de organizarse dentro del territorio nacional que, si bien todavía no hay un patrón de organización, ni tendencias a la expansión, es a partir de este momento que podrá observarse.

\section{La Gran Dieta Simbólica Escocesa de los Estados Unidos Mexicanos}

Muchos son los autores que han abordado la cuestión de la Gran Dieta Simbólica Escocesa de los Estados Unidos Mexicanos, en tanto que unos autores plantean que se pudo tratar de un asunto interno de la masonería para mediar las diferencias entre ritos, filosofía, etcétera; para otros se trató más de una cuestión de orden propuesto por el Rito de York. Incluso, la interpretación de Luis J. Zalce y Rodríguez es que se pudo tratar de una imposición a la "libertad de simbolismo" dentro de la masonería; para José Luis Trueba Lara fue una cuestión de control y de orden desde el poder para poner en cintura a las sociedades secretas; por último, Rogelio Aragón presenta puntos de vista imparciales que buscan entender el fenómeno social y explicarlo a través de su contexto.

6 De Villarreal, Trabajo Potente, 59-60. 
Se tienen en cuenta estos trabajos y también las posibilidades de lectura del fenómeno social a las que pueden contribuir, no es el objeto de este estudio volver a explicar la Gran Dieta Simbólica Escocesa de los Estados Unidos Mexicanos, que ha sido previamente abordada en estudios específicos, sino mencionar algunos puntos de este periodo de la masonería y su impacto a nivel nacional para entender sus repercusiones en el en el desarrollo y expansión regional de la masonería en Nuevo León durante este periodo.

De acuerdo con el autor José Luis Trueba Lara, en su libro Masones en México. Historia del Poder Oculto, Porfirio Díaz en un intento por controlar a las sociedades secretas se creó una sociedad secreta que presionó a los miembros del Rito Nacional Mexicano, y la mayoría de ellos, seguidores de Ignacio Manuel Altamirano, a que definieran su apoyo a Díaz, o a estar abiertamente en su contra. Altamirano aceptó la propuesta y fue nombrado cónsul general de México en España, lo que a su vez fue entendido como un reconocimiento a su vida política y literaria, quedando así nula la oposición masónica hacia Porfirio Díaz. ${ }^{8}$

Es en este contexto que en el año de 1889 iniciaron conversaciones de paz aquellos sobrevivientes del Supremo Gran Oriente de los Estados Unidos Mexicanos y los integrantes del Supremo Consejo del Rito Escocés Antiguo y Aceptado, dando como resultado la creación de La Gran Dieta Simbólica de los Estados Unidos Mexicanos en el año de 189o, que incorporó a su vez a los miembros más destacados del Rito Nacional Mexicano, siendo su objetivo la centralización de las actividades de las sociedades secretas del país, nombrando como gran maestro a Porfirio Díaz. ${ }^{9}$

Sin embargo, este intento de centralización fracasó porque no todas las logias se incorporaron. Apelando su autonomía e independencia, hubo logias de talante radical que se negaron a integrarse, aunado a los abusos de autoridad de la administración de Ermilo G. Cantón, desde las cuestiones internas, hasta la expulsión de los hermanos Jesús Medina, y de Ignacio A. de la Peña por denunciar los abusos de Cantón, entre otras causas, influyeron para que Díaz interviniese a poner orden. Así las cosas, en el año de 1895 Porfirio Díaz renunció a su cargo de gran maestro y otras logias siguieron su ejemplo, de modo que para el año de 1901 la Gran Dieta Simbólica había desaparecido, no obstante que su sede, el Supremo Gran Oriente había cerrado sus puertas en $1898 . .^{10}$

7 José Luis Trueba Lara, Masones en México. Historia del Poder Oculto (Ciudad de México: Santillana Ediciones Generales, 2012), 258.

8 Trueba, Masones en México, 258.

9 Trueba, Masones en México, 259.

10 Trueba, Masones en México, 259. 


\section{La expansión de la masonería en Nuevo León durante la administración del general Bernardo Reyes, 1905-1909}

Regresando al contexto local del Estado de Nuevo León, la masonería no siempre contó con el apoyo del general Bernardo Reyes. De acuerdo con Rogelio Aragón, en correspondencia entre Bernardo Reyes y Porfirio Díaz el día 18 de agosto de 1890 mencionaba que Ermilio G. Cantón "se encontraba negociando la adhesión de la masonería de aquel Estado a la Gran Dieta Simbólica y que había propuesto a Juan Weber -un alemán avecindado en México desde hacía treinta años- que presidiera la logia neoleonesa." De lo anterior, Rogelio Aragón infiere la libertad que el presidente Díaz dio al gobernador Reyes de unificar la masonería del Estado o no. ${ }^{11}$

Así mismo, continúa Rogelio Aragón refiriendo que el gobernador Bernardo Reyes en su exposición a Porfirio Díaz respecto de la situación de la masonería en el Estado, confesó que nada "por mejorar la situación de la masonería en su estado, sino que intencionalmente la había dejado mal dirigida y había permitido que los «trabajos relativos» vayan languideciendo” y que jamás había visitado una logia ni había estado en contacto con los masones, bajo el pretexto de que se hallaba "irregular". ${ }^{2}$

Continuando con Rogelio Aragón, refiere que Porfirio Díaz por su parte respondió a Bernardo Reyes aconsejándole primero considerara a la masonería como "una institución que bien organizada y manejada prestará algún servicio”, pero que en caso de que la persona propuesta, Juan Weber, no fuera propicio para la dirección a la masonería nuevoleonesa, lo mejor sería que dejara que las cosas continuaran su curso, es decir, dejar "languidecer los trabajos" y que el mismo Porfirio Díaz notificaría a la Dirección Central para que dejase de insistir en la unificación de la masonería en el Estado. ${ }^{3}$

Al respecto, en el libro El General Bernardo Reyes que escribió Eberhardt Víctor Niemeyer Jr., documento de carácter biográfico centrado en su carrera pública, citó a su vez la correspondencia entre Bernardo Reyes y Porfirio Díaz. Decía en una carta fechada el día 27 de agosto de 1891 que no consideraba necesaria la masonería en el Estado, confiando más en los avances del gobierno local en materia de instrucción pública para combatir la influencia de la Iglesia católica:

[...] dada la circunstancia de que ni hay partido conservador ni el clero de esta Diócesis es desobediente a las autoridades. Cierto es que, como en todas partes pretende apoderarse del espiritu de los jóvenes por medio de la instrucción caprichosa que les prodiga al efecto; pero la Masonería que aquí se pusiera a trabajar en nada podría contrarrestar los avances de nuestros enemigos en ese camino y sí lo puede hacer este Gobierno porque cada día reúne más elementos en favor de la instrucción pública que es el terreno escogido para el combate. ${ }^{14}$

11 Correspondencia de Porfirio Díaz en el Acervo Histórico de la Universidad Iberoamericana (a partir de ahora CPD), legajo 16, caja 7, doctos. o03291-003292; legajo 16, caja 18, docto. 008525; legajo 17, caja 3, docto. 001478, citado por Aragón, "Porfirio Díaz y la «Gran Dieta Simbólica»", 142.

12 CPD, legajo 16, caja 7, doctos. 003291-003292; legajo 16, caja 18, docto. 008525; legajo 17, caja 3, docto. o01478, citado por Aragón, "Porfirio Díaz y la «Gran Dieta Simbólica»", 142.

13 GPD, legajo 16, caja 7, doctos. 003291-003292; legajo 16, caja 18, docto. 008525; legajo 17, caja 3, docto. o01478, citado por Aragón, "Porfirio Díaz y la «Gran Dieta Simbólica»", 142.

14 Víctor Niemeyer Jr., El General Bernardo Reyes (Monterrey: Universidad Autónoma de Nuevo León y Museo de Historia 
De esta manera, la instrucción pública contó con el impulso del Gobierno del Estado para la elaboración de una reforma general de la educación primaria, habiendo detectado el problema la falta de uniformidad de los métodos educativos y textos de apoyo de toda la entidad federativa. Una vez que se hicieron públicas las recomendaciones de diferentes congresos de educación, se hicieron cambios y sugerencias por el Consejo del Estado de Instrucción Pública, así como del cuerpo administrativo de la Preparatoria del Estado y de colegios profesionales para la elaboración de una propuesta de ley que el general Reyes presentó a la Legislatura el 3 de diciembre de $1891{ }^{15}$

Una vez concretada en la Ciudad de México la Gran Dieta Simbólica en 1891, la Gran Logia Independiente del Estado "Unión” No. 7 emitió una circular para que suspendieran trabajos, se declarase "en sueños" hasta nueva orden junto con los demás bajo su jurisdicción. ${ }^{16}$ A pesar de que se recibió la circular y de la posterior disolución de la mencionada Gran Dieta Simbólica, la nueva orden nunca llegó y casi todos los talleres acordaron continuar sus actividades masónicas, hecho que fortaleció la influencia de las grandes logias "Valle de México y "Unida Mexicana" en territorio nuevoleonés, puesto que siguieron ejerciendo autoridad sobre varios talleres ${ }^{17}$.

Así, después de los estragos de la administración de la Gran Dieta Simbólica ${ }^{18}$, de acuerdo con Zalce y Rodríguez, el 24 de junio de 1905 se constituyó formalmente la Gran

Mexicanam 2008), 94. Refiere a su vez el libro Héctor González, Siglo y Medio de Cultura Nuevoleonesa (Monterrey: Ediciones Botas, 1946), 213.

15 Niemeyer, El General Bernardo Reyes, 95.

16 Zalce, Historia de la Masonería, tomo I, 445.

17 Zalce, Historia de la Masonería, tomo II, 301.

18 Zalce Historia de la Masonería, tomo I, 445. El autor se basó en el libro de Richard E. Chism, Una contribución a la Historia Masónica de México (México: Imprenta de El Minero Mexicano, 1899), menciona que la Gran Dieta Simbólica fue perniciosa para la masonería nacional dadas las pretensiones reguladoras.

De Villarreal, Trabajo Potente, coincide en sus puntos de vista en que este organismo limitó la libertad de las logias, cuando menos.

Trueba, Masones en México, entiende a la Gran Dieta Simbólica como un organismo con pretensiones de controlar a las sociedades secretas del país con el visto bueno de Porfirio Díaz.

Aragón, "Porfirio Díaz y la «Gran Dieta Simbólica»", 137-148, presenta hechos y desarrollo de la Gran Dieta Simbólica, pero además plantea la posibilidad de que Porfirio Díaz no estuvo involucrado en la creación de este organismo.

Carlos Francisco Martínez Moreno, “Coaliciones y traiciones masónicas. De la primera reelección de Porfirio Díaz a los inicios de la revolución mexicana, 1887-1911”, REHMLAC+ 7, no. 2 (diciembre 2015-abril 2016): 149-177, http://dx.doi.org/10.15517/rehmlac.v7i2.22853. A su vez plantea que fueron factores externos y la manera en que se condujo la Gran Dieta Simbólica lo que causó descontento a otras logias de extranjeros como Anáhuac, Toltec y Germania, mismas que hicieron presión tanto en Inglaterra como en Estados Unidos para desconocer y que se disolviera este organismo, pidiendo además la separación de Porfirio Díaz e Ignacio Mariscal.

Salvador Cárdenas, "La lucha entre masones y católicos en el Porfiriato. La creación de la Gran Dieta Simbólica de México en 1890”, en Masonería y sociedades secretas en México, coords. José Luis Soberanes y Carlos Francisco Martínez Moreno (Ciudad de México: Universidad Nacional Autónoma de México, 2018), refiere del periódico El Tiempo la nota "Festividad masónica" del día 24 de diciembre de 1895. Menciona que la creación de la Gran Dieta Simbólica obedeció a propósitos políticos para asegurar su reelección, además de que esto fue percibido por la comunidad católica de la Ciudad de México como un "renuevo de la masonería mexicana y de su programa ideológicos, lo cual traería como consecuencia un aumento notable de la presencia de las logias en la sociedad y de «acción anticatólica» entre las élites gobernantes del país”, 281.

Carlos Valdés, "Estimación sobre la influencia de los masones en la Constitución de 1917 y su diseño", en Influencia de la Masonería en la Constitución de 1917, coord. Manuel Jiménez (Ciudad de México: Secretaría de Cultura: Instituto Nacional de Estudios Históricos de las Revoluciones de México, 2016), menciona que la Gran Dieta Simbólica "integró a las principales organizaciones en una «superestructura» que las cohesionó en una autoridad superior sin disolver los ritos, quedando Porfirio Díaz como su Gran Maestro. El ascenso meteórico y capacidad de la Gran Dieta para integrar armónicamente a los principales ritos (juntando las escisiones previas de los ritos Escocés, Nacional Mexicano y Yorquino), parece haber dependido del peso ganado bajo la sombra y favoritismo de la figura presidencial. Que todos los ritos se unieran en una única cúpula superior implicaba una situación anómala de centralización, bajo la sombra de una autoridad política, lo cual reflejaba un éxito del proyecto centralizador en Porfirio Díaz" [sic], 44, además de mencionar que durante la "paz porfiriana" el modelo de la logia-partido empezaba a disolverse, 43 . 
Logia de Nuevo León a partir de tres Respetables Logias Simbólicas: "Obreros del Silencio" No. 1, "Constancia" No. 2, y "Victoria" No. $3^{19}$, recibiendo su carta patente extendida por la Gran Logia de Veracruz "Unida Mexicana”.

Fig. 1. Retrato del gran maestro de la Gran Logia del Estado de .Nuevo León, general Bernardo Reyes, 1905-1909, en la oficina administrativa de la misma.



Fuente: Elaboración propia.

En lo que respecta al proyecto del primigenio recinto del templo masónico, este recibió el impulso del gran maestro, gobernador del Estado y jefe militar, el general Bernardo Reyes, quien el 5 de septiembre de 1905 expidió una circular a los talleres de la jurisdicción en la que comunicaba el proyecto "de construir un edificio que reuniera las condiciones necesarias para las reuniones y el mejor desarrollo de los trabajos litúrgicos y sociales; además, pedía que el excedente de los fondos de cada Taller se unieran al fondo aportado por todos con igual propósito." ${ }^{20}$ 
El proyecto de construcción del edificio fue elaborado por el ingeniero civil y masón Porfirio Treviño Arreola ${ }^{21}$ y quedó terminado para su inauguración y consagración el día 27 de diciembre de 1906 con motivo del solsticio de invierno ${ }^{22}$. El inmueble estuvo ubicado en la calle Lerdo de Tejada (actualmente calle Mariano Escobedo), casi en la esquina de la calle Manuel María del Llano, que ocupó un predio de 42.00 metros de fondo por 43.00 metros de frente ${ }^{23}$.

Fig. 2. Gran Logia de.Nuevo León, ca. 1915.

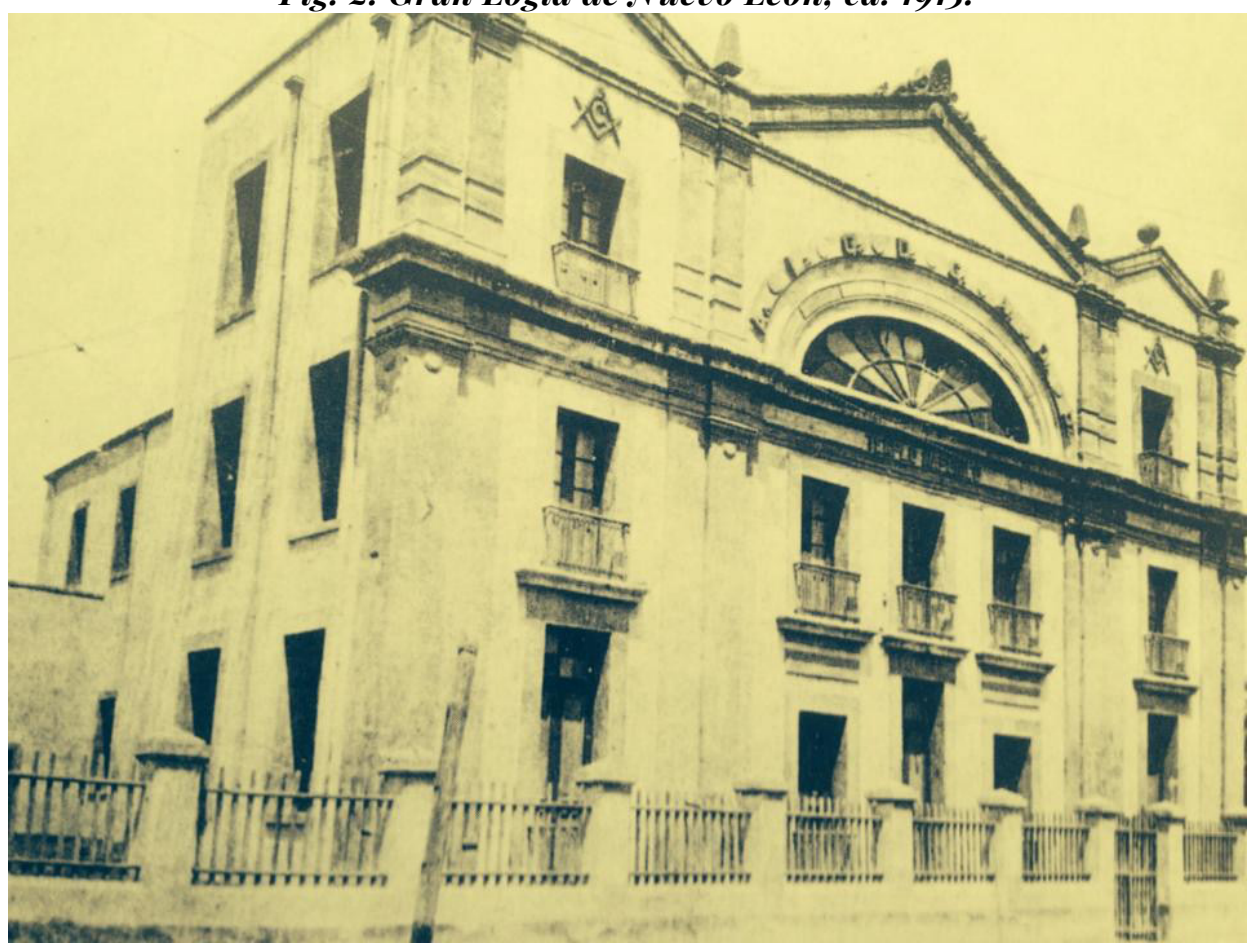

Fuente: https://www.facebook.com/photo.

php?fbid=10204066717055737\&set=g.802887916407595\&type=1\&theater Original: Autor no identificado. Templo Masónico II. 1915. Fondo Sandoval-Lagrange. Instituto de Estudios Superiores de Monterrey. Fototeca Tecnológico de Monterrey. Código 77o. http:/hdl.handle. net/11285/590191

Refiriendo el discurso que pronunció Bernardo Reyes el 24 de junio de 1906 y que fue reproducido en el Boletín de la Gran Logia de Libres y Aceptados Masones del Estado de Nuevo León, mismo que a su vez fue citado en el artículo de Marco Antonio Flores Zavala, La masonería en el centro-norte de México, 1869-1914, respecto a la organización de la Gran Logia del Estado de Nuevo León, así como de la expansión que empezaba a experimentar esta sociedad en el Estado, lo expresó en los siguientes términos:

Dejadme, rápido, trazar la trayectoria brillante de nuestra ascensión.

Tres logias simbólicas vinieron a la existencia con crepitaciones de ricas savias, en septiembre del año pasado, y a ellas se unieron otros dos talleres que guardaban el fuego sagrado en 
este desierto neolonés, y se formó el gran núcleo que nos dio la soberanía legitimada con el establecimiento de la Gran Logia, en 24 de junio último, y luego instalamos un taller más, en julio siguiente, y concedimos a dos grupos que se hallan fuera de esta capital, dispensa para preparar su organización en forma, y aquí venimos hoy a legitimar al que se encontraba en Monterrey en ese estado; y así la constelación neolonesa masónica, brilla; y en el espacio, como nubes baladas por crepúsculos, flotan estandartes; y esas realidades vivientes, son el testimonio glorioso de nuestra labor fertilizadora. ${ }^{24}$

Fig. 3. Estandartes de 1905 y de 1925 de la Gran Logia del Estado de .Nuevo León, mostrando una alegoría de Hércules en una forja.

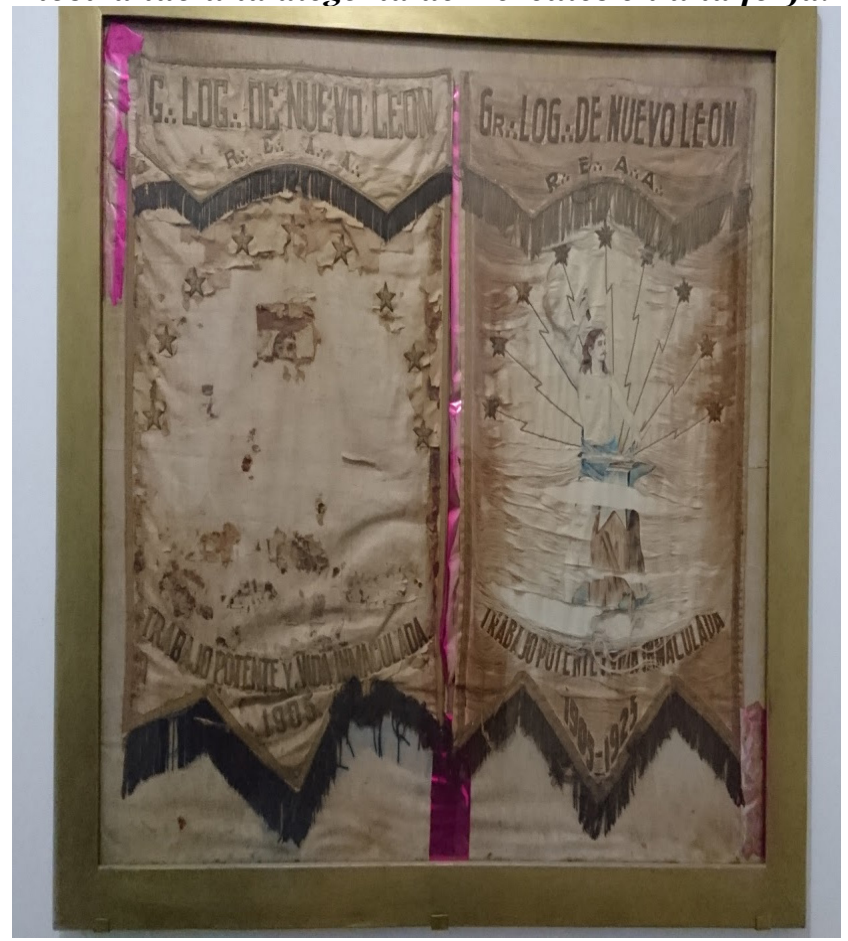

Fuente: Elaboración propia.

\section{La ocupación socio-espacial de la masonería en Nuevo León durante la administración del general Bernardo Reyes, 1905-1909}

Es a partir de este momento que la masonería experimentó su expansión hacia otros municipios en los años siguientes, entendiendo dicha expansión como la consolidación del área de influencia y control político en la región, medible en logias simbólicas. Sin embargo, aunque no es materia de este estudio, cabe la posibilidad de que también en estos talleres pudo haber gente afecta al general Reyes y que a su vez pudo haber estado involucrada en los círculos de apoyo político que años después postularon al general Reyes como candidato y visible sucesor del presidente Porfirio Díaz. En palabras de su biógrafo, Eberhardt Víctor Niemeyer Jr.: "Bajo la guía de don Bernardo la masonería se convirtió en fuerte, disciplinada y activa políticamente. Cada masón de Nuevo León era partidario suyo y cada logia un centro de una amplia influencia reyista.”25

24 "Discurso solsticial del M. R. Gran Maestro [Bernardo Reyes, 24 de junio de 1906]", en Boletín de la Gran Logia de Libres y Aceptados Masones del Estado de Nuevo León... Monterrey, 1906, citado por Marco Antonio Flores Zavala, "La masonería en el centro-norte de México, 1869 -1914", REHMLAC+ 6, no. 1 (mayo-diciembre 2014): 119, https:// revistas.ucr.ac.cr/index.php/rehmlac/article/view/15229/14528

25 Niemeyer, El General Bernardo Reyes, 218. A su vez lo enuncia Zalce, Historia de la Masonería, tomo I, 444-446. 
A su vez, en la ciudad de Monterrey se suscitó en este contexto una etapa de un marcado jacobinismo en la que por una parte, a nivel de traza urbana, se cambió hacia 1902 el nombre de la calle del Teatro por el de calle del general Escobedo y en 1906 se cambió el nombre de la calle de San Francisco por el de la calle de Ocampo ${ }^{26}$, ambos masones ilustres; por otra parte, en lo que respecta al contexto social y comportamientos, refiere Isidro Vizcaya Canales en su libro Los orígenes de la industrialización de Monterrey que "Era una época de jacobinismo exaltado. La mayoría de los hombres se mostraban indiferentes, cuando no abiertamente hostiles a toda idea religiosa. Era raro el varón que se atrevía a pisar un templo, por temor a ser señalado como fanático y retardatario” ${ }^{27}$.

Por su parte, Juan Zapata Nova en su libro El mercado de las conciencias (Sectas y cultos en Monterrey), estudio sociológico enfocado a las religiones, cultos y sectas en la ciudad a lo largo de su historia, refiere que durante el gobierno del general Reyes la industrialización de Monterrey coincidió con la ideología del positivismo científico que estuvo en boga a finales del siglo antepasado. Este desarrollo estuvo a su vez acompañado por intercambios culturales que se propiciaron en los que las logias masónicas en aquel Monterrey industrial del gobierno reyista. ${ }^{28}$

Continuando con la descripción de este clima social en la ciudad de Monterrey, Juan Zapata menciona que antes de la presencia y del impulso de la masonería en el Estado, tampoco hubo una experiencia significativa religiosa, por lo que se reforzó el laicismo. Además los intercambios culturales y las subsecuentes inmigraciones de extranjeros procedentes de Europa y Estados Unidos, que en buena parte eran protestantes de nacimiento y miembros activos de logias mexicanas, también conforman la situación nuevoleonesa:

Los constructores de Monterrey en su gran mayoría eran miembros activos de alguna logia masónica. La religión se reservaba a las mujeres para la preservación de las buenas costumbres quienes si contaban con escuelas de religiosas. En esa época los señores acudían, ante la insistencia familiar, a realizar una visita a la Iglesia una vez por año frecuentemente en Navidad, eran contadas las familias practicantes en unidad ${ }^{29}$.

En lo que respecta a la expansión en la entidad federativa, la ocupación socio-espacial de la masonería en Nuevo León resulta de interés cuando se observa que en la Fig.3. Tảbla de logias simbólicas fundadas en Nuevo León, 1905-1910 queda registrada la logia simbólica llamada "Obreros del Misterio" No. 16, misma que fue fundada en Congregación Colombia el día 31 de diciembre de 1906.

Es pertinente anotar que la Congregación Colombia es un poblado en la frontera norte del Estado de Nuevo León, a un kilómetro antes de llegar al Río Bravo, límite orográfico entre México y los Estados Unidos, y cuya fundación data del año 1892. Así, se puede inferir que el inicio de actividades de dicha logia también "se enmarca en un amplio proceso de búsqueda

26 Isidro Vizcaya, Los orígenes de la industrialización de Monterrey (Monterrey: Fondo Editorial de Nuevo León: ITESM, 2006), 113, citando el periódico La Voz de Nuevo León del 9 de junio de 1906 en el que se publicó lo siguiente: "La calle de San Francisco que lo tiene (este nombre) por encontrarse en ella los restos de un convento así llamado lo que no amerita denominación de una calle en una ciudad progresista”.

27 Vizcaya, Los origenes de la industrialización, 113.

28 Juan Zapata, El mercado de las conciencias (Sectas y cultos en Monterrey) (Monterrey: Ediciones Castillo, 1990), 75.

29 Zapata, El mercado de las conciencias, 74. 
de control político, militar y fiscal del territorio. Con ello de una búsqueda urgente para definir de límites interestatales encaminado a ubicar los terrenos baldíos para convertirlos en propiedad privada." ${ }^{\circ}$

Además, esto supone un compromiso o interés de impulsar la expansión de la masonería en Nuevo León que bien pudo tratarse de una acción de proselitismo de la masonería para captar adeptos. También cabe la posibilidad de que Bernardo Reyes haya seguido la recomendación de Porfirio Díaz de que la masonería era "una institución que bien organizada y manejada prestará algún servicio” ${ }^{31}$ que, para este propósito, sería más fácil de gobernar en un territorio unificado. No obstante, el sentido pragmático del general Reyes lo constató su hijo, el escritor Alfonso Reyes Ochoa, cuando describió que:

[...] Después, durante su desempeño político en Nuevo León, la masonería nunca fue irrespetuosa para ninguna creencia, y la aprovechó como medio de crear una cohesión entre clases trabajadoras - que aún no había sindicatos-, y de ponerlas en contacto directo y fácil con el gobernante. ${ }^{2}$

La tabla de la figura 3 es un registro de la expansión de la masonería en la que se recopilaron datos consultados en el trabajo del masón Ernesto de Villarreal Cantú Trabajo Potente, Vida Inmaculada: Medio Siglo de Cultura Masónica, 1905-1955, quien registró hasta el año de 1956 la historia de la masonería nuevoleonesa. Así, como se observa en la tabla, una vez disuelta la Gran Dieta Simbólica, en los últimos años del régimen porfirista fue cuando en Nuevo León la masonería experimentó uno de sus crecimientos más álgidos.

Fig. 3. Tabla de logias simbólicas fundadas en .Nuevo León, 1905-1910

\begin{tabular}{|c|c|c|c|c|c|c|}
\hline \multicolumn{7}{|c|}{$\begin{array}{l}\text { TABLA DE LOGIAS SIMBÓLICAS FUNDADAS EN NUEVO LEÓN } \\
\text { DURANTE LA GRAN MAESTRÍA DEL GENERAL BERNARDO REYES }\end{array}$} \\
\hline LOGIA & MUNICIPIO & FUNDACIÓN & $\begin{array}{l}\text { CARTA } \\
\text { PATENTE }\end{array}$ & $\begin{array}{l}\text { FECHA DE } \\
\text { CONSAGRACIÓN }\end{array}$ & TEMPLO & EDIFICIO \\
\hline $\begin{array}{l}\text { "Obreros del } \\
\text { Silencio" No. } 1\end{array}$ & Monterrey, N.L. & $\begin{array}{l}08 \text { de septiembre } \\
\text { de } 1904\end{array}$ & $\begin{array}{l}24 \text { de junio de } \\
1905\end{array}$ & $\begin{array}{l}27 \text { de diciembre de } \\
1906\end{array}$ & $\begin{array}{l}\text { Benito } \\
\text { Juárez }\end{array}$ & $\begin{array}{l}\text { Gran Logia del Estado } \\
\text { de Nuevo León }\end{array}$ \\
\hline "Constancia" No. 2 & Monterrey, N.L. & $\begin{array}{l}12 \text { de septiembre } \\
\text { de } 1904\end{array}$ & $\begin{array}{l}24 \text { de junio de } \\
1905\end{array}$ & $\begin{array}{l}27 \text { de diciembre de } \\
1906\end{array}$ & $\begin{array}{l}\text { César } \\
\text { Decanini } \\
\text { Flores }\end{array}$ & $\begin{array}{l}\text { Gran Logia del Estado } \\
\text { de Nuevo León }\end{array}$ \\
\hline "Victoria" No. 3 & Monterrey, N.L. & $\begin{array}{l}13 \text { de septiembre } \\
\text { de } 1904\end{array}$ & $\begin{array}{l}24 \text { de junio de } \\
1905\end{array}$ & $\begin{array}{l}27 \text { de diciembre de } \\
1906\end{array}$ & $\begin{array}{l}\text { José María } \\
\text { Maldonado }\end{array}$ & $\begin{array}{l}\text { Gran Logia del Estado } \\
\text { de Nuevo León }\end{array}$ \\
\hline $\begin{array}{l}\text { "Guardianes del } \\
\text { Misterio" No. } 4\end{array}$ & Monterrey, N.L. & $\begin{array}{l}08 \text { de julio de } \\
1905\end{array}$ & & & $\begin{array}{l}\text { José María } \\
\text { Maldonado }\end{array}$ & $\begin{array}{l}\text { Gran Logia del Estado } \\
\text { de Nuevo León }\end{array}$ \\
\hline "Fénix" No. 5 & Monterrey, N.L. & $\begin{array}{l}18 \text { de febrero de } \\
1904\end{array}$ & $\begin{array}{l}12 \text { de julio de } \\
1905\end{array}$ & 11 de julio de 1905 & $\begin{array}{l}\text { Dr. Ángel } \\
\text { Martínez } \\
\text { Villarreal }\end{array}$ & $\begin{array}{l}\text { Gran Logia del Estado } \\
\text { de Nuevo León }\end{array}$ \\
\hline $\begin{array}{l}\text { "Tolerancia } \\
\text { Masónica" No. } 6\end{array}$ & Monterrey, N.L. & & $\begin{array}{l}12 \text { de julio de } \\
1905\end{array}$ & 11 de julio de 1905 & $\begin{array}{l}\text { Benito } \\
\text { Juárez }\end{array}$ & $\begin{array}{l}\text { Gran Logia del Estado } \\
\text { de Nuevo León }\end{array}$ \\
\hline LOGIA & MUNICIPIO & FUNDACIÓN & $\begin{array}{l}\text { CARTA } \\
\text { PATENTE }\end{array}$ & $\begin{array}{l}\text { FECHA DE } \\
\text { CONSAGRACIÓN }\end{array}$ & TEMPLO & EDIFICIO \\
\hline
\end{tabular}

30 EL-CUARTEL-DE-COLOMBIA-NL. "El Cuartel de Colombia, N.L.: El cuartel de una frontera. Por: César Morado Macías” http://el-cuartel-de-colombia-nl.blogspot.com/2010/o8/el-cuartel-colombia-nl.html

31 Aragón, "Porfirio Díaz y la «Gran Dieta Simbólica»", 142.

32 Alfonso Reyes, "Memorias”, en Obras Completas, tomo XXIV (Ciudad de México: Fondo de Cultura Económica, 1990), 424. 


\begin{tabular}{|c|c|c|c|c|c|}
\hline $\begin{array}{l}\text { "General Mariano } \\
\text { Escobedo" No. } 9\end{array}$ & $\begin{array}{l}\text { Santiago, Nuevo } \\
\text { León. }\end{array}$ & $\begin{array}{l}18 \text { de agosto de } \\
1905\end{array}$ & $\begin{array}{l}23 \text { de agosto } \\
\text { de } 1930\end{array}$ & $\begin{array}{l}\text { General } \\
\text { Mariano } \\
\text { Escobedo }\end{array}$ & $\begin{array}{l}\text { Respetable Logia } \\
\text { Simbólica } \\
\text { "General Mariano } \\
\text { Escobedo" No. } 9\end{array}$ \\
\hline $\begin{array}{l}\text { "Chee Kung Tong" } \\
\text { No. } 12\end{array}$ & Monterrey, N.L. & $\begin{array}{l}11 \text { de abril de } \\
1906\end{array}$ & & $\begin{array}{l}\text { Chee } \\
\text { Kung Tong }\end{array}$ & $\begin{array}{l}\text { Respetable Logia } \\
\text { Simbólica } \\
\text { "Chee Kung Tong" } \\
\text { No. } 12\end{array}$ \\
\hline $\begin{array}{l}\text { "Obreros del } \\
\text { Misterio" No. } 16 \\
\text { (En Sueños) }\end{array}$ & $\begin{array}{l}\text { Congregación } \\
\text { de Colombia, } \\
\text { N.L. }\end{array}$ & $\begin{array}{l}31 \text { de diciembre } \\
\text { de } 1906\end{array}$ & & & \\
\hline "Aurora" No. 17 & García, N.L. & $\begin{array}{l}17 \text { de febrero de } \\
1907\end{array}$ & & & \\
\hline "Hidalgo" No. 18 & $\begin{array}{l}\text { General Terán, } \\
\text { N.L. }\end{array}$ & $\begin{array}{l}09 \text { de abril de } \\
1907\end{array}$ & & Hidalgo & $\begin{array}{l}\text { Respetable Logia } \\
\text { Simbólica } \\
\text { "Hidalgo" No. } 18\end{array}$ \\
\hline $\begin{array}{l}\text { “Dr. José Eleuterio } \\
\text { González" No. } 19\end{array}$ & $\begin{array}{l}\text { Bustamante, } \\
\text { N.L. }\end{array}$ & $\begin{array}{l}15 \text { de junio de } \\
1905 \\
\text { (Reanudación de } \\
\text { trabajos) }\end{array}$ & & $\begin{array}{l}\text { Dr. } \\
\text { Eleuterio } \\
\text { González }\end{array}$ & $\begin{array}{l}\text { Respetable Logia } \\
\text { Simbólica } \\
\text { "Dr. Eleuterio } \\
\text { González" No. } 19\end{array}$ \\
\hline $\begin{array}{l}\text { "Guadalupe } \\
\text { Victoria" No. } 21 \\
\text { (En Sueños) }\end{array}$ & $\begin{array}{l}\text { Salinas Victoria, } \\
\text { N.L. }\end{array}$ & $\begin{array}{l}11 \text { de agosto de } \\
1907\end{array}$ & & & \\
\hline "Morelos" No. 22 & $\begin{array}{l}\text { Montemorelos, } \\
\text { N.L. }\end{array}$ & $\begin{array}{l}28 \text { de enero de } \\
1908\end{array}$ & & Morelos & $\begin{array}{l}\text { Respetable Logia } \\
\text { Simbólica } \\
\text { "Morelos" No. } 22\end{array}$ \\
\hline $\begin{array}{l}\text { "Guardianes de la } \\
\text { Constitución" } \\
\text { (En Sueños) }\end{array}$ & $\begin{array}{l}\text { Santa Catarina, } \\
\text { N.L. }\end{array}$ & $\begin{array}{l}03 \text { de marzo de } \\
1908\end{array}$ & & & \\
\hline $\begin{array}{l}\text { "Obreros de la Luz" } \\
\text { No. } 32 \\
\text { (Primera Época) } \\
\text { En Sueños desde } \\
1909\end{array}$ & $\begin{array}{l}\text { Sabinas Hidal- } \\
\text { go, N.L. }\end{array}$ & $\begin{array}{l}14 \text { de mayo de } \\
1906\end{array}$ & & $\begin{array}{l}\text { Obreros } \\
\text { de la Luz }\end{array}$ & $\begin{array}{l}\text { Respetable Logia } \\
\text { Simbólica } \\
\text { "Obreros de la Luz" } \\
\text { No. } 32\end{array}$ \\
\hline $\begin{array}{l}\text { "Melchor Ocampo" } \\
\text { (Primera Época) }\end{array}$ & Allende, N.L. & $\begin{array}{l}20 \text { de enero de } \\
1907\end{array}$ & & $\begin{array}{l}\text { Melchor } \\
\text { Ocampo }\end{array}$ & $\begin{array}{l}\text { Respetable Logia } \\
\text { Simbólica } \\
\text { "Melchor Ocampo" }\end{array}$ \\
\hline
\end{tabular}

Fuente: Elaboración propia con datos del libro Apuntes para la Historia de la Masonería en México (De mis lecturas y mis recuerdos) de Luis J. Zalce y Rodríguez, así como del libro Trabajo Potente Vida Inmaculada: Medio Siglo de Cultura Masónica 1905-1955 de Ernesto de Villarreal Cantú.

En la figura 4 se puede apreciar un mapa digital del noreste de México y hay colocadas unas chinchetas que refieren las ubicaciones aproximadas de las logias simbólicas, para tener una idea de la expansión en el Estado y sus áreas de influencia dentro de cada municipalidad en esta etapa de la masonería en Nuevo León. En color azul cerúleo está marcada la ubicación actual del nuevo edificio (1961) de la Gran Logia del Estado de Nuevo León; en amarillo están referidos los talleres originales que todavía siguen en funciones y, finalmente, en gris las 
logias simbólicas que suspendieron sus actividades, hayan sido declaradas "en sueños", o bien que "abatieron columnas".

Fig. 4. Localización geográfica de las logias simbólicas, $1905-1910$.

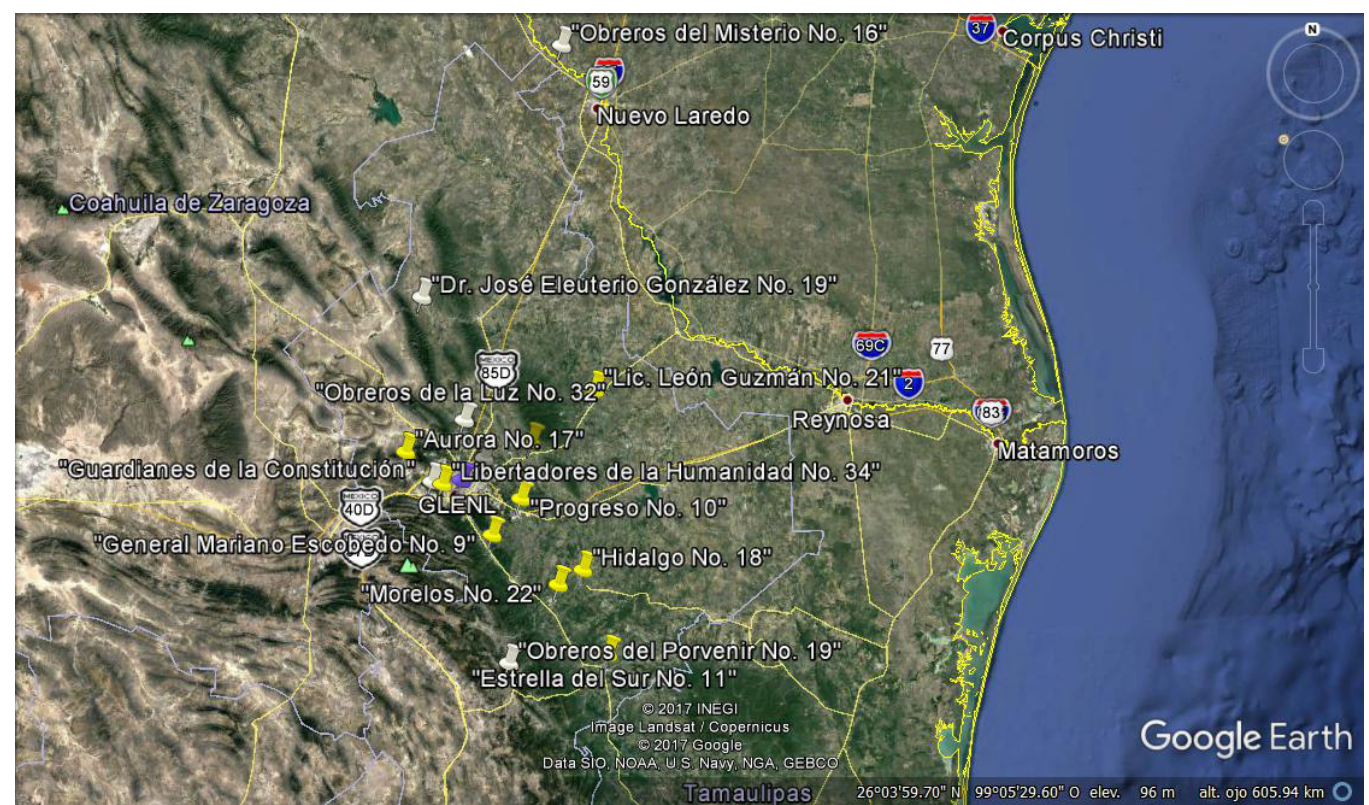

Fuente: Elaboración propia. Se usó la herramienta Google Earth con base en los datos recopilados en la tabla.

Es preciso mencionar que no todas las ubicaciones de las logias son exactas, puesto que algunas de ellas suspendieron sus actividades definitivamente, por lo que se ignora el paradero de sus vestigios. Ya que se regularizó la situación socio-política de México y de que finalizara la Revolución mexicana, en Nuevo León, a mediados de la década de 1920, es cuando se tiene registro de una nueva etapa en la expansión de la masonería nuevoleonesa con la fundación de la logia "Libertadores de la Humanidad" No. 34 en el municipio de San Pedro Garza García, Nuevo León, México, cuando inició actividades el 3 de abril de 1925.

Si procedemos a identificar la organización de la expansión de la masonería en el Estado de Nuevo León se observa un patrón tendiente a estar organizado mediante la presencia de un cuerpo rector -en este estudio la Gran Logia del Estado de Nuevo León; las demás logias simbólicas de la jurisdicción o landmark y su emplazamiento se caracteriza de una logia simbólica por cada municipio del Estado. Ahora bien, si trazamos una línea desde el centro -Gran Logia del Estado de Nuevo León-, hacia las demás logias simbólicas, de tal manera que, si se observara desde arriba, curiosamente emula la forma de una red de tipo estrella, aunque deformada por la curiosa forma romboidal que tiene el Estado de Nuevo León. 


\section{La masonería en Nuevo León durante la administración del general}

José María Mier, 1909-1911

Cuando el general Bernardo Reyes partió hacia Europa en un exilio disfrazado de comisión militar, haya sido por su lealtad al presidente Díaz en su calidad de hermano masón, o bien, que las ambiciones de Bernardo Reyes a la Presidencia fueron evidentes y Porfirio Díaz se negó a dejar el poder y mucho menos compartirlo, la masonería nuevoleonesa quedó bajo dirección del general José María Mier durante un breve período. En este tiempo se fundaron los talleres "Independencia” No. 26 en Monterrey -que luego cambió su nombre a "Socialista Independencia"-, y el taller "Simbolismo Libre" No. 38 en Doctor González, ambas en el año de 1910.



Fuente: D.R. Instituto Nacional de Antropología e Historia, México. https://mediateca.inah.gob.mx/islandora_74/islandora/object/fotografia:504

A pesar de los esfuerzos del general Mier por impulsar el crecimiento de la masonería en el Estado, tuvo que dejar la ciudad porque fue a combatir a las fuerzas de levantamiento de la Revolución de 1910 que, debido a su lealtad al gobierno del polémico usurpador, el general Victoriano Huerta, lo llevó morir en batalla en el Estado de Jalisco en el año de 1914.

En lo que respecta al conflicto bélico de la Revolución mexicana para la situación de la masonería en Nuevo León, hay que considerar que durante el tiempo que tuvo lugar el conflicto armado, una vez electo como gran maestro de la Gran Logia del Estado de Nuevo León, el Sr. Atanasio Carillo declaró suspendidos los trabajos masónicos en el Estado desde 1914 hasta 1917. Posteriormente, se reanudaron las actividades cuando volvió a ser electo para el cargo en el ejercicio de $1918^{33}$. 


\section{Conclusiones}

En los inicios de la masonería nuevoleonesa, como se ha visto, las logias estaban dispersas y en un intento de unificar y controlar a las sociedades secretas, se creó la Gran Dieta Simbólica, organismo centralizador que pretendió concentrar y regular a todos los talleres de todas las obediencias, incluso permitiendo la admisión de mujeres a sus talleres. ${ }^{34}$ Sin embargo, este intento fue infructuoso y comenzaron otras potencias o grandes logias a desconocer la Gran Dieta Simbólica y empezó lo que Marco Antonio Flores Zavala identificó como la etapa de la confederación de las grandes logias ${ }^{35}$.

Identificando el patrón de la expansión de la masonería en el Estado de Nuevo León se observa lo siguiente: 1) la presencia de un cuerpo rector o potencia en un centro -en este estudio la Gran Logia del Estado de Nuevo León-; 2) las demás logias simbólicas de la jurisdicción y su emplazamiento en cada municipio. Si se traza una línea desde el centro -Gran Logia del Estado de Nuevo León-, hacia las demás logias simbólicas, de tal manera que, vista desde arriba, este trazo emula la forma de una red de tipo estrella.

Una analogía de esta distribución se puede encontrar en la descripción del estandarte de la Gran Logia del Estado de Nuevo León que describe Ernesto de Villarreal Cantú, cuando cita el documento que explica la selección del semidiós griego Hércules, como alegoría al trabajo de la masonería nuevoleonesa, quien está representado trabajando en una forja con mazo, golpeando un yunque del que emanan nueve chispas que a su vez representan a los talleres fundados durante la gran maestría del general Bernardo Reyes. ${ }^{36}$

La operación de este patrón consta de cómo se asientan las logias simbólicas en un punto, recibiendo una carta patente de una gran logia o potencia externa que los reconoce como cuerpo regular; la instancia a definir sus reglamentos; designar su cuadro de autoridades y determinar cuándo decidan reunirse. Una vez establecidos los cuerpos o talleres regulares y en comunicación con una potencia externa, estos pueden decidir conformar una gran logia, reuniendo como mínimo tres talleres, contando para tal efecto con su respectiva carta patente. Una vez conformada como gran logia o gran potencia, esta a su vez puede autorizar la formación y operación de otros talleres regulares bajo su jurisdicción.

34 Martínez Moreno, “Coaliciones y traiciones masónicas”, 155, refiriendo entre las causas de la disolución de la Gran Dieta Simbólica de los Estados Unidos Mexicanos que "se unieron a la protesta en contra suya las logias de extranjeros Anáhuac, Toltec y Germania y finalmente lograron que fuera desconocida por las obediencias de Inglaterra y de Estados Unidos, con ello la obligaron a desterrar la masonería femenina y hacer obligatorio el uso de la biblia y, al final de agosto, a que renunciaran a sus cargos en ella el presidente de la república y gran maestro Porfirio Díaz y el secretario de relaciones exteriores Ignacio Mariscal”. Theodore Sutton Parvin, Mexican Masonry (Iowa: Cedar Rapids, May 17th,1897). Richard E. Chism, Una contribución, 127, citado por Carlos Francisco Martínez Moreno, "Auge y Caída de la Masonería en México en el Siglo XIX. La Exclusión de la Mujer bajo la mirada del Discurso Masónico de Laureana Wright González", REHMLAC+ 4, no. 2 (diciembre 2012-abril 2013): 129-155, https://revistas.ucr.ac.cr/index.php/rehmlac/article/view/12188/11471

35 Flores Zavala, "La masonería en el centro-norte”, 116, señala como cuarto ciclo de organización de la masonería a aquel comprendido entre los años de 1900-1936 que se caracterizó por que "El primer dilema fue el tipo de estructura que debería tener: Confederación de Grandes Logias o una Gran Logia Nacional. Luego está, qué instancia era la adecuada para reconocer la regularidad y la legitimidad de una gran logia estatal.”

36 De Villarreal, Trabajo Potente, 207, citando un documento del Archivo de la Gran Logia del Estado de Nuevo León, "Sobre un campo blanco orlado de oro, se ostenta la figura de un Hércules golpeando sobre un yunque, del que se desprenden chispas de oro en forma de estrella equivalentes al número de Logias existentes en aquel tiempo". Resaltando sobre el blanco purísimo de su fondo está inscrita la siguiente leyenda: «TRABAJO POTENTE. VIDA INMACULADA» [sic]. 
Este patrón de distribución geográfica encontrado en Nuevo León en el periodo estudiado, 1905-1911, corresponde más al periodo de organización de la masonería que citó Marco Antonio Flores Zavala, es decir, al de la conformación de la Confederación de Grandes Logias. Pero si se pretende indagar en antecedentes de cómo es que llegó la masonería al Estado de Nuevo León, un indicio pertinente es el trabajo de María Eugenia Vázquez Semadeni, quien, en el Tomo I, Migraciones, de la colección 300 Años: Masonerías y Masones 1717-2017, en su capítulo Del Mar a la Política. Masonería en Nueva España / México, 1816-1823, observó un patrón de difusión de la masonería en México similar al descrito por Maurice Agulhon, quien a su vez estudió la expansión o difusión de la masonería en Provenza hacia el año de1968, es decir, este patrón de establecer logias masónicas en los puertos y de ahí continuar hacia el interior del país ${ }^{37}$.

Sin embargo, realizar un estudio especializado en el rastrear los inicios de la masonería en el Estado de Nuevo León, así como de la identificación de las distintas grandes logias, extranjeras o nacionales, que otorgaron cartas patentes además de rastrear el origen de las mismas, resulta de importancia para comprender mejor la historiografía mexicana y la presencia de la masonería entendida como organización que se ha adaptado a los cambios de la historia. Por ejemplo, el modelo de las logias-partido y sus tendencias políticas, permitiría evaluar mejor los contextos históricos tanto del país como de los Estados y regiones, no solo de la conformación de esta organización, sino de los procesos humanos y desarrollos de entidades federativas del país.

Puntualmente, de la observación de la forma de organización de las logias masónicas, de su obediencia a organismos de mayor jerarquía, se infiere una centralización de la autoridad misma que extiende su dominio sobre las demás logias masónicas o talleres diseminados en el Estado. Este patrón de organización se entiende como parte del uso y de la ocupación socio-espacial de la ciudad y en una escala mayor, del territorio político de Nuevo León por medio del proselitismo que hizo la masonería en la búsqueda de contextos fértiles y propensos para llevar a cabo sus ideales.

Esta ocupación social de la masonería implica una reapropiación del territorio a través de un orden con base en una organización jerarquizada dentro de un ordenamiento territorial que se ha desarrollado al mismo tiempo que la masonería, también en la jerga masónica conocidos como landmarks, pero que tiene mayor precedencia porque de este ordenamiento (trazas urbanas, jurisdicciones territoriales federativas, organización, usos del espacio) se desprenden pautas para la organización de jurisdicciones territoriales de la masonería y su presencia en el entramado urbano por medio de tipologías urbanas como fueron en su momento sus edificios sede (grandes logias), comúnmente en las cabeceras municipales, y las demás logias (respetables logias simbólicas), por lo general, una por cada municipio.

37 María Eugenia Vázquez Semadeni, “Del Mar a la Política. Masonería en Nueva España / México, 1816-1823”, en 300 Años: Masonerías y Masones 1717-2017. Tomo I. Migraciones, eds. Ricardo Martínez Esquivel, Yván Pozuelo Andrés y Aragón (Ciudad de México: Palabra de Clío, 2017), 144. 
Entonces, cuando observamos la expansión regional de la masonería en Nuevo León y consideramos la descripción que proporcionó Juan Zapata al respecto de este clima social en la ciudad de Monterrey, podemos encontrar una fuerte tendencia laica que, si bien no era nueva en el Estado, recibió un impulso de la masonería y que se vio influido a su vez por la suscitación de intercambios culturales así como de las subsecuentes inmigraciones de extranjeros procedentes de Europa y Estados Unidos que, como se mencionó previamente, en buena parte eran protestantes de nacimiento y miembros activos de logias masónicas mexicanas.

\section{Bibliografía}

Alanís, J. Centenario de la Resp.•. Log.•. Simb.•” Gral. Mariano Escobedo No. 9 Or.•. de Santiago, N.L. 1905-2005. Monterrey: Imprenta de la Gran Logia del Estado de Nuevo León. 2005.

Aragón, Rogelio. "Porfirio Díaz y la Gran Dieta Simbólica: ¿La masonería mexicana bajo control?". REHMLAC+ 7, no. 2 (diciembre 2015-abril 2016): 137-148. http://dx.doi.org/10.15517/ rehmlac.v7i2.22695

Casasola, Gustavo. José María Mier, general, retrato. 1910. Fototeca Nacional. Dirección del Sistema Nacional de Fototecas. D.R. Instituto Nacional de Antropología e Historia, México. https://mediateca.inah.gob.mx/islandora 74/islandora/object/fotografia:504

De Villarreal, Ernesto. Trabajo Potente, Vida Inmaculada: Medio Siglo de Cultura Masónica, 1905-1955. Monterrey: Imprenta de la Gran Logia del Estado de Nuevo León. 1956.

EL-CUARTEL-DE-COLOMBIA-NL. "El Cuartel de Colombia, N.L.: El cuartel de

una frontera. Por: César Morado Macías”. http://el-cuartel-de-colombia-nl.blogspot. com/2010/08/el-cuartel-colombia-nl.html

Flores Zavala, Marco Antonio. "La masonería en el centro-norte de México, 1869-1914". REHMLAC+ 6, no. 1 (mayo-diciembre 2014): 109-130. https://revistas.ucr.ac.cr/index.php/ rehmlac/article/view/15229/14528

González, H. Siglo y Medio de Cultura Nuevoleonesa. Monterrey: Ediciones Botas. 1946.

Jiménez, Manuel, coord. Influencia de la masonería en la Constitución de 191\%. Ciudad de México: Secretaría de Cultura: Instituto Nacional de Estudios Históricos de las Revoluciones de México, 2016.

Martínez Moreno, Carlos Francisco. "Auge y Caída de la Masonería en México en el Siglo XIX. La Exclusión de la Mujer bajo la mirada del Discurso Masónico de Laureana Wright González". REHMLAC+, 4, no. 2 (diciembre 2012-abril 2013): 130-155. https://revistas.ucr. ac.cr/index.php/rehmlac/article/view/12188/11471

Martínez Moreno, Carlos Francisco. “Coaliciones y traiciones masónicas. De la primera reelección de Porfirio Díaz a los inicios de la revolución mexicana, 1887-1911”. REHMLAC+ 7 , no. 2 (diciembre 2015-abril 2016): 137-148. http://dx.doi.org/10.15517/rehmlac.v7i2.22853 
Martínez Moreno, Carlos Francisco y José Luis Soberanes coords. Masonería y sociedades secretas en México. Ciudad de México: Universidad Nacional Autónoma de México. 2018.

Niemeyer Jr., Víctor. El General Bernardo Reyes. Monterrey: Universidad Autónoma de Nuevo León y Museo de Historia Mexicana. 2008. $3^{\text {a }}$ ed.

Respetable Logia Simbólica Libertadores No. 434. "Glosario de términos masónicos". https://logialibertadoresblog.wordpress.com/glosario-de-terminos-masonicos/

Reyes, Alfonso. Memorias. Obras Completas, t. XXIV. Ciudad de México: Fondo de Cultura Económica, 1990.

Templo Masónico II. 1915. Fondo Sandoval-Lagrange. Instituto de Estudios Superiores de Monterrey. Fototeca Tecnológico de Monterrey. Código 770. http://hdl.handle. net/11285/590191. Facebook. Monterrey Antiguo. https://www.facebook.com/photo. php?fbid $=10204066717055737 \&$ set $=$ g.802887916407595\&type $=1 \&$ theater

Trueba, José. Masones en México. Historia del Poder Oculto. Ciudad de México: Santillana Ediciones Generales. 2012.

Vázquez, María. "Del Mar a la Política. Masonería en Nueva España / México, 1816-1823”. En 300 Años: Masonerías y Masones 1717-2017. Tomo I. Migraciones. Editado por Ricardo Martínez Esquivel, Yván Pozuelo Andrés, Rogelio Aragón. Ciudad de México: Editorial Palabra de Clío. 2017.

Vizcaya, I. Los orígenes de la industrialización de Monterrey. Monterrey: Fondo Editorial de Nuevo León e ITESM. 2006.

Zalce y Rodríguez, Luis. Apuntes para la Historia de la Masonería en México (De mis lecturas $y$ mis recuerdos) Primer y Segundo Tomo. Ciudad de México: Talleres Tipográficos de la Penitenciaría del Distrito Federal, 1950.

Zapata, Juan. El mercado de las conciencias (Sectas y cultos en Monterrey). Monterrey: Ediciones Castillo. 1990. 